\title{
O Poema do mar, do poeta cabo-verdiano Jorge Barbosa
}

\author{
José Antonio Santos de OLIVEIRA ${ }^{1}$ \\ Amanda Ramalho de Freitas BRITO ${ }^{2}$ \\ ${ }^{1}$ Graduando em Letras na Universidade Estadual de Alagoas (UNEAL). Membro do grupo de Estudos em \\ Literatura Comparada da Universidade Federal da Paraíba (UFPB). E-mail: jaletras1997@gmail.com \\ ${ }^{1}$ Doutora em Letras pela UFPB. Professora de Literaturas de Língua Portuguesa da UFPB. E-mail: \\ amandaramalhobrito@gmail.com
}

\begin{abstract}
Resumo - A poesia cabo-verdiana inicia seu itinerário literário a partir da revista de Cabo Verde, mas foi no decênio de 1930, com a Revista Claridade, que os ideais da outrora colônia portuguesa angariaram maior expressão artística e crítica da realidade, inspirados pelos escritores do modernismo brasileiro. Entre os poetas cabo-verdianos, tem-se Jorge Barbosa, conhecido pelo seu fascínio em relação à obra poética de Manuel Bandeira, cujas temáticas refletiam sobre as condições geográficas das ilhas de Cabo Verde, reverberadas por meio da presença recorrente da insularidade e a dicotomia ir/ficar. Nesse sentido, a presente comunicação intenta promover uma exegese da obra Poema do mar, presente no livro Ambiente, de 1941. Discutindo como o autor constrói sua perspectiva crítica do lugar onde morava, no qual se pode verificar relações pertinentes entre o texto literário e as condições sociais, culminando, por conseguinte, no desejo utópico de evasão do arquipélago, já que esse anseio por liberdade se concretiza apenas no plano imaginativo. Ademais, observar-se-á como os traços da literatura brasileira, sobretudo, do estilo bandeiriano, emergem no poema supracitado. Portanto, este trabalho será embasado nas reflexões de Ferreira (1977), Gomes (2006) e Plaviski (2014).
\end{abstract}

Palavras-chave: Poesia de Cabo verde. Utopia. Jorge Barbosa.

Abstract - Cape Verdean poetry begins its literary itinerary from the Cape Verde magazine, but it was in the 1930s, with the Revista Claridade, that the ideals of the former Portuguese colony gained greater artistic and critical expression of reality, inspired by the writers of Brazilian modernism. Among Cape Verdean poets, there is Jorge Barbosa, known for his fascination in relation to the poetic work of Manuel Bandeira, whose themes reflected on the geographical conditions of the islands of Cape Verde, reverberated through the recurring presence of insularity and the dichotomy go / stay. In this sense, this communication intends to promote an exegesis of the work Poema do mar, present in the book Ambiente, from 1941. Discussing how the author constructs his critical perspective of the place where he lived, in which one can verify pertinent relationships between the literary text and the social conditions, culminating, therefore, in the utopian desire for evasion of the archipelago, since this yearning for freedom is realized only on the imaginative plane. In addition, it will be observed how the features of Brazilian literature, above all, of the Bandeirian style, emerge in

\footnotetext{
${ }^{1}$ Graduando em Letras na Universidade Estadual de Alagoas (UNEAL). Membro do grupo de Estudos em Literatura Comparada da Universidade Federal da Paraíba (UFPB). E-mail: jaletras1997@ gmail.com

${ }^{2}$ Doutora em Letras pela UFPB. Professora de Literaturas de Língua Portuguesa da UFPB. E-mail: amandaramalhobrito@gmail.com
} 
the aforementioned poem. Therefore, this work will be based on the reflections of Ferreira (1977), Gomes (2006) and Plaviski (2014).

Keywords: Cabe verde poetry. Utopia. Jorge Barbosa.

\section{Introdução}

Leva-me contigo

Navio.

Mas torna-me a trazer.

Jorge Barbosa

Cabo Verde é um país africano composto por dez ilhas e, assim como o Brasil, foi outrora colônia de Portugal. Quando os portugueses chegaram na região ocidental da África encontraram o arquipélago desabitado, este fato pode ser explicado devido às condições climáticas do lugar, seco e distante do restante do continente. Além disso, conforme será visto nas próximas letras, esse afastamento de Cabo Verde em relação aos outros países é relevante para compreender a produção literária, marcada, sobretudo, pelas questões de insularidade e anseio de partida dos cabo-verdianos.

Como a literatura está atrelada à sociedade e aos diversos contextos de produção, pelos quais autores perpassam em suas existências, sabe-se que esta arte reflete/pensa sobre os acontecimentos multifacetados da história. Somando a isto, compreende-se que cada indivíduo apresenta uma perspectiva singular de observar o mundo e ressignifica nos meandros literários. Nesse sentido, a partir de suas próprias leituras e de suas vivências, o texto literário granjeia forma e se insere no âmbito reflexivo do ser humano.

Dessa forma, Jorge Barbosa concretiza-se como um exemplo profícuo das reflexões trazidas nessas primeiras letras, já que o autor supracitado aborda em sua poesia os traços inerentes do lugar onde morava, bem como inseria, em suas obras, suas perspectivas críticas de mundo, ou seja, usava de seus estigmas individuais para produzir literatura, problematizando suas leituras sobre autores brasileiros, mormente, trazendo tendências estilísticas/temáticas, presentes na literatura do poeta Manuel Bandeira.

Ademais, o poeta enfatizado, buscava dialogar com a poesia bandeiriana, concatenando suas produções, mesmo que implicitamente, ao poema Vou-me embora pra Pasárgada, não escondendo sua admiração exacerbada em relação à literatura brasileira, ao 
mesmo tempo que conseguia traduzir a essência do desejo onírico de Bandeira para as obras cabo-verdianas. Nesse contexto, vale ressaltar, que o poeta Jorge Barbosa, assim como Baltasar Lopes, foram os principais disseminadores da literatura brasileira nas ilhas caboverdianas, fazendo da semelhança cultural uma ponte entre países e literaturas, ligados por processos históricos similares.

O poema do mar, do escritor cabo-verdiano, auxilia na compreensão do fazer poético barbosiano, tendo em vista que ele sintetiza o itinerário poético do autor, emergindo seu caráter evasivo/dialógico. A tendência evacionista recupera a semântica do poema brasileiro citado, além de evidenciar o elo entre as literaturas. Por essas razões, pensa-se a relação de influência na obra estudada, conforme discute Carvalhal (2006) e, indubitavelmente, vê-se as idiossincrasias de Cabo Verde nos versos conflituosos de Jorge Barbosa.

\section{A literatura cabo-verdiana}

Para compreender as nuances, que compõem a produção literária do país estudado, faz-se necessário deambular diacronicamente nos acontecimentos significativos de Cabo Verde. O primeiro deles, obviamente, foi a sua descoberta no século $\mathrm{XV}$, no qual o processo de colonização se concretizou de maneira diferente, se comparar aos outros países da África Lusófona: Angola, São Tomé e Príncipe, Moçambique e Guiné-Bissau. Essa distinção se acentua justamente, porque o arquipélago não era povoado por volta de 1460 , nesse caso, o povoamento aconteceu, lógico, com os portugueses que buscavam explorar o território e com negros, que eram levados a força para as ilhas, tornando-se, por conseguinte, escravos em terras distintas, deixando seus familiares e traços de sua cultura.

O contato entre esses dois povos, por sua vez, possibilitou a criação de uma população mestiça nas ilhas cabo-verdianas. Tal miscigenação provocou o atrelamento até mesmo dos vários dialetos africanos com a língua portuguesa, gerando, destarte, a língua crioula. Esta, embora não seja oficial em Cabo Verde e nem seja estudada nas escolas, é a mais falada nos ambientes informais do arquipélago. Nesse sentido, é pertinente depreender esse contexto, uma vez que as produções literárias deste lugar, diferentemente dos outros países africanos, não problematizaram questões referentes à negritude, restringindo-se até então, a descrição geográfica de Cabo Verde concatenada às vivências peculiares dos autores. De acordo com Secco: 
Em Cabo Verde, desde a década de 30, Claridade já clamava por uma poesia autêntica, que buscava afirmar a cabo-verdianidade. Essa poética, ao contrário do que ocorre em Moçambique e Angola, na década de 50, não reivindicava os temas da negritude, tendo em vista a predominância mestiça em Cabo Verde, cujas ilhas, desertas na ocasião da descoberta, foram povoadas por portugueses oriundos da Madeira e negros vindos da Guiné. (SECCO, 2011, N/P).

Além disso, a literatura cabo-verdiana, como procurava uma forma mais original de se fazer literatura, fugindo dos arquétipos da literatura portuguesa, encontrou na Literatura Brasileira, a possibilidade de elaborar textos, que refletissem sobre suas próprias condições de vida, ao mesmo tempo que se sentissem livres para produzirem, por meio de uma estrutura/estética inovadora, textos fora dos padrões da época, mesmo que já no final do século XIX, com a Revista de Cabo Verde, busca-se construir obras voltadas a certas características da antiga colônia. Garmes (2006, p. 21) explica que "ao valorizar uma literatura de cunho cabo-verdiana, estimularam a produção local e colocaram de lado a tradicional submissão do colonizado em relação ao colonizador”. Dessa forma, observa-se o papel relevante dessa revista, já que foi responsável por introduzir o desejo por uma literatura desconectada em relação às produções do país, que os explorava.

A Revista Claridade concentra o maior número de obras, inspiradas pela literatura brasileira, tendo em vista que, a partir de 1930, as produções do arquipélago buscam veementemente liberdade artística, assim como o modernismo no Brasil instaurou novas perspectivas de fazer literatura. Para Ferreira,

Considera-se a autêntica literatura cabo-verdiana aquela que exprime a caboverdianidade, ou seja o conjunto de textos cujo enunciado reflecte o real cabo-verdiano. Com frequência, e alguma veemência, a partir de década de trinta, a questão ficou devidamente clarificada e demarcada, embora nem sempre isenta de excessos, como quase sempre acontece em momentos de ruptura (e a parte de responsabilidade que nisso nos cabe não a queremos enjeitar). (FERREIRA, 1977, p. 24).

Nesse sentido, Jorge Barbosa caracteriza-se como o primeiro autor a desenvolver essa literatura autônoma e, por esse motivo, tornou-se o principal expoente da literatura caboverdiana, rompendo com as antigas formas de se fazer poesia. Em meio às rupturas estruturais nos textos poéticos, oriundas da efervescência claridosa, houve uma proximidade exacerbada 
com o pasargadismo ${ }^{3}$, o que em 1958, com o grupo Suplemento cultural, veio a ser criticado pelos poetas póstumos, o mais conhecido e significativo desse período foi Ovídio Martins, cujas obras teciam críticas vociferas à influência da literatura bandeiriana nas obras da revista Claridade, escritas, sobretudo, por Jorge Barbosa e Osvaldo de Alcântara.

\section{O Poema do mar: diálogo e utopia}

A primeira estrofe do poema esmiuçado carrega consigo o teor dramático das palavras de Jorge Barbosa, que logo desenharão os traços dicotômicos de sua poesia, produzida por meio de elementos inerentes à localidade cabo-verdiana. Nesse caso, o escritor transforma o espaço físico de sua existência no espaço, onde ele habita e no espaço presente em suas vísceras, ou melhor, o termo mar empregado pelo poeta se refere, decerto, ao conjunto de águas que cercavam o arquipélago e, ao mesmo tempo, conota os sentimentos profundos trazidos pelo escritor.

Desse modo, é factível perceber a inquietude do eu-lírico frente aos desafios de viver em um lugar isolado, no qual se podia sair daquela realidade a partir do devaneio. Além disso, pode-se observar a presença da anáfora nos versos sempre, compostos por somente uma palavra cada, sabe-se, que faz parte do estilo cabo-verdiano de externar a solidão daqueles habitantes, ilhados no sentido literal da palavra. Stoenesco $(1999$, p. 57) explica que "[...] cada palavra forma um verso, contribuindo neste caso para acentuar a solidão e o tormento destes homens espantosamente bloqueados". Tal prisão, nesse período da literatura cabo-verdiana, acontece devido ao período de colonização pelo qual ainda passava Cabo Verde, já que apenas veio se tornar independente na segunda metade do século XX, e, conforme já assinalado anteriormente, por causa das condições geográficas dos nativos do arquipélago, no qual não possuíam contato mais estreito com as outras comunidades africanas.

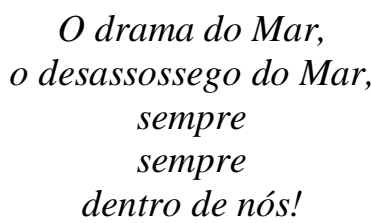

\footnotetext{
3 Na literatura cabo-verdiana, por problematizarem demasiado Vou-me embora pra Pasárgada, de Manuel Bandeira, houve uma ligação semântica entre o termo evasionismo e pasargadismo. Dessa forma, ambas as palavras remetem ao desejo utópico dos poetas de Cabo Verde de saírem de sua terra natal. (tamanho da fonte de rodapé: 10).
} 
A segunda estrofe situa os movimentos pertencentes ao mar, estes, por sua vez, aparecem a partir de formas verbais no gerúndio, ratificando a ideia de continuidade e, por conseguinte, construindo o espaço observatório do eu-lírico, que percebia as ações provocadas pelo mar como nefastas nesse fragmento. Tanto é, que o verbo prender, se referindo às ilhas, indica a situação confinadora, no qual os cabo-verdianos são submetidos, uma vez que viver nessas regiões configura-se como permanecer cercado com efeito por águas, bem como não ter possibilidade de sair do arquipélago somente com forças humanas, isto quer dizer que, ao mesmo tempo que o mar mostrava um caminho possível de evasão para os habitantes de caboverde, também ele, o mar, mostrava-se como principal empecilho para saída das terras caboverdianas. Ferreira (1977, p. 36), comentando as especificidades da literatura cabo-verdiana no decênio de 1930, explica que "Barbosa procede a uma radiografia do drama social do homem cabo-verdiano: a seca, a fome, a emigração, o isolamento, a insularidade, e o mar como estrada mítica". Ao se referir sobre estes dois últimos tópicos, a fim de discutir sobre o trecho analisado nesse momento do trabalho, verifica-se que o movimento do mar desgastando as rochas acontece paulatinamente, assim como a sensação do eu-lírico de sofrer o conflito de ficar ilhado, somente contemplando os sons emitidos pelo mar, sem participar das viagens feitas por meio de barcos que chegavam em Cabo Verde.

\section{O mar! \\ Cercado \\ Prendendo nossas ilhas, \\ Desgastando as rochas das nossas ilhas! \\ Deixando o esmalte do seu salitre nas faces dos pescadores \\ Rocando nas areias das nossas praias \\ Batendo a sua voz de encontro aos montes \\ Baloiçando os barquinhos de pau que vão por estas costas...}

A evocação do mar era sinônimo de súplica para os cabo-verdianos, fomentados pelo exagero na escrita poética e pela forte influência do catolicismo na antiga colônia portuguesa, também se demonstrava traços de sua religiosidade nos versos, como pedido aos céus para aliviar-se das condições climáticas desfavoráveis. Segundo Gomes (2006, p. 166) "Temas como o martírio da terra-mãe, a aridez, a seca, a fome são constantes do olhar cabo-verdiano para dentro, assim como os temas de insularidade como drama geográfico e da emigração ou evasão como saídas possíveis para essa problemática”. Essa migração pode ser vista na próxima estrofe, quando o eu-lírico lamenta ficar confinado em Cabo-verde, vendo pessoas 
que chegavam nas ilhas, estas pobres não de beleza, mas sim de circunstâncias favoráveis para produção alimentícia etc. Ademais, depreende-se que a nostalgia designada de países distantes é uma clara referência ao Brasil, visto que Jorge Barbosa almejava conhecer o pais sul-americano, cujos laços com a cultura africana são visíveis e pertinentes para compreensão cultural tanto brasileira, como dos povos africanos, trazendo, essa raiz histórica entre Brasil e Cabo Verde como elo profícuo na literatura.

\author{
O mar! \\ Pondo rezas nos lábios, \\ Deixando nos olhos dos que ficaram \\ A nostalgia designada de países distantes \\ Que chegam até nós nas estampas das ilustrações \\ Nas fitas de cinema \\ E nesse ar de outros climas que trazem passageiros \\ Quando desembarcam para ver a pobreza da terra!
}

Apesar das condições geográficas restritas, trazidas pelo mar. Percebe-se que este elemento não consegue retirar os sonhos dos indivíduos, ou melhor, o eu-lírico busca no plano onírico forças para resistir aos conflitos particulares de sua existência, embora sejam provocados devido às limitações de Cabo Verde. Segundo Barriel “[...] a Utopia, não é o produto de um delírio, mas nasceu das necessidades concretas de combater o destino". Nesse sentido, o poeta se utiliza desse meio para poder libertar-se das amarras físicas de Cabo Verde, embora existam duas formas de combater os desafios da vida, o primeiro é enfrentar de frente, lutando pelos objetivos com todas as forças e o segundo, por sua vez, acontece quando o sujeito apenas idealiza sair das dificuldades por meio do sonho. A essa última, Plaviski (2014) definiu como utopia escapista, pois aparece na literatura, quando o eu-lírico/ narrador de um texto transcende apenas imaginando, recusando-se combater as opressões que o circundam.

\title{
O mar!
}

A esperança da carta distante

Que não chegue mais! ...

Segundo Coutinho e Carvalhal (1990, p. 334) "a literatura é um amálgama, um complexo, e não uma série de obras individuais. É um ciclo e uma soma. Uma realidade cultural está na origem desta disciplina: condições interligadas efetivamente ou idealisticamente unem uma literatura às outras". Nesse contexto, entender a literatura como 
processo dialógico, que possibilita aos autores conversarem literariamente com outros escritores, independentemente de suas localidades, estabelecendo relação direta ou não, é pertinente para perceber o alcance e como o texto literário se adapta às nuances do contexto histórico/geográfico, para construção de obras, cujas especificidades refletem às suas condições intrínsecas, ademais, pensar a relação de influência entre textos literários possibilita uma exegese mais apurada da literatura produzida em uma determinada região, fomentando a visão panorâmica de suas produções.

Um exemplo profícuo da influência/intertextualidade pode ser visto na próxima estrofe a ser verificada, visto que se observa diálogo estreito com a literatura bandeiriana. Basta compreender como Jorge Barbosa traz a contação de história para explicar sua nostalgia em relação ao passado, mas trazendo elementos pertencentes à realidade de cabo verde ${ }^{4}$. Saudade também presente em diversas obras do percussor do modernismo brasileiro, sobretudo no poema Vou-me embora pra Pasárgada ${ }^{5}$, quando Manuel Bandeira diz se refere às histórias contadas por Rosa, embora a mística da contação de histórias do Bandeira faça parte da tradição oral viva no território brasileiro, o que não impede o contato sistemático entre as produções, pelo contrário, realça a metamorfose da literatura no contato com culturas diferentes.

\section{O mar!}

Saudades dos velhos marinheiros contando histórias dos velhos de tempos passados Histórias da baleia que uma vez virou canoa.. De bebedeiras, de rixas, de mulheres nos portos estrangeiros...

A próxima estrofe funciona como antítese da primeira, já que agora elenca os fatos positivos da insularidade, enaltecendo os personagens/objetos, que constroem Cabo Verde, como se o eu lírico demonstrasse a melhor parte de viver no arquipélago, isto é, o contato com a Morna, gênero musical do arquipélago; a presença de negras hábeis e corpos atraentes das moças cabo-verdianas. Nesse sentido, evidencia o lado negativo de sair do arquipélago, tendo em vista que os migrantes perderão essa parte marcante de Cabo Verde, vendo-a apenas por meio do sonho. Isto releva a disparidade entre o ir e ficar, já que sempre terão percas.

\footnotetext{
${ }^{4}$ Refere-se aos marinheiros e histórias contadas em Cabo Verde.
} 


\author{
O mar! \\ Dentro de todos nós \\ No canto da Morna, \\ No corpo das raparigas morenas, \\ Nas coxas ágeis das pretas, \\ No desejo de viagem que fica em sonhos de muita gente!
}

Para finalizar toda a narrativa, o eu lírico traz o chamado figurativo que o mar faz a ele, pedindo-o para evadir do arquipélago, mas por amor a sua pátria e/ou medo de situações futuras, sente-se obrigado a ficar nas ilhas. Outro pormenor importante nos versos do poema, indubitavelmente, é a presença da terceira pessoa do plural, embora o poeta construa sua lírica a partir da função emotiva da linguagem, no geral, realizada na primeira do singular. Ferreira explica:

Jorge Barbosa é a voz plural que amiúde recorre a expressões como esta: «voz da nossa gente», a transformar o seu discurso na voz colectiva. A enumeração repetitiva, no caso presente adjectivada, mas noutros substantivada, aliada à evocação ou ao apelo afectivo, num recurso continuado à função expressiva. (FERREIRA, 1977. p. 37).

Assim sendo, a pessoa do discurso usada por Jorge faz de sua poesia uma obra individual, mas que expõe as dificuldades de um povo, sofredor por causa da insularidade. Portanto, a dramaticidade de Barbosa se concatena aos problemas presentes em Cabo Verde e por isso a voz plural, a fim de chamar a atenção dos cabo-verdianos nos seus versos, por vezes, utópicos.

Este convite de toda a hora

Que o mar nos para a evasão!

Este desespero de querer partir

E ter que ficar!

A última estrofe sintetiza a postura evacional de Jorge Barbosa, a qual se constrói a partir da dualidade ( ir e ficar) do eu lírico, que usa a imagem do mar, do seu apartamento com outros povos e lugares, com o intuito de externar o caráter melancólico de sua voz, saudosa de terras nunca habitadas por ele. 


\section{Considerações Finais}

Pensar a literatura cabo-verdiana mostra-se relevante para compreender certas especificidades da literatura brasileira e como esta literatura se metamorfoseou em outros espaços, angariando notoriedade nas produções artísticas de Cabo Verde. Tal contato entre países perpassou os limites geográficos/históricos, cuja contribuição aconteceu, sobretudo, no fomento a novas percepções literárias do arquipélago, inspiradas pela onda modernista, evidentemente pelo evacionismo trazido por Manuel Bandeira.

Manuel Bandeira, por sua vez, é a principal referência em termos de lírica, percebida pelos autores de Cabo Verde ao longo de sua formação literária, a partir da revista Claridade. Este poeta também foi responsável por moldar as obras de Jorge Barbosa, no que se diz repito às temáticas abordadas pelo claridoso, uma vez que o poeta cabo-verdiano adota a essência de Vou-me embora pra Pasárgada, respirando o caráter evasivo do poema brasileiro em suas obras, entre elas, em $O$ poema do mar.

Nesse sentido, o poema esmiuçado por seu trabalho exibe o cerne da literatura barbosiana, por conseguinte, da literatura de Cabo Verde, isto é, O poema do mar carrega consigo os temas problematizados pelo arquipélago, de modo a descortinar a pobreza, o clima e a migração como elementos substanciais na produção literária dos ilhéus e, concatenado a isto, por fim, mas não menos importante, reflete sobre o conflito interno dos habitantes de Cabo verde, manifestado pela discrepância entre sair ou ficar do lugar onde moravam. Ademais, percebeu-se como o poema de Jorge Barbosa reflete sobre a condição solitária do sujeito, assim como Bandeira deixa subtendida essa mesma condição, mesmo que implicitamente, em Vou-me embora pra Pasárgada. 
Referências

CARVALHAL, Tania Franco. Literatura comparada. 4 ed. São Paulo, Ática, 2006.

BANDEIRA, M. Libertinagem. $2^{\mathrm{a}}$ ed. São Paulo: Global, 2013.

BARRIEL, C. E. O. Utopia, distopia e história. In: Editora da Morus. (Org.). Utopia e Renascimento: 2005, p. 4-10.

FERREIRA, M. Literaturas Africanas de expressão portuguesa I. $1^{\text {a }}$ ed. Amadora: Oficinas Gráficas da Livraria Bertrand Venda Nova, 1977.

GARMES, H. O pioneirismo político e literário da Revista de Carbo Verde. Revista

GOMES, S. C. "Rostos, gestos, falas, olhares, de mulher: o texto literário de autoria feminina em cabo verde". In: CHAVES \& MACEDO. (org). Marcas da diferença: As Literaturas Africanas de Língua Portuguesa. São Paulo: Alameda, 2006.

PAVLISKI, E. "Os horizontes do utopismo". In: 1984: a distopia do indivíduo sob controle [online]. Ponta Grossa: Editora UEPG, 2014, pp. 17-90. ISBN 978-85-7798-218-9. Available from SciELO Books <http://books.scielo.org>.

SECCO, C. L. T. As Literaturas Africanas em Língua Portuguesa: Um percurso de cantos e desencantos. Revista Vernaculum: Flor do Lácio. Petrópolis: V.3, n.3 (2011).

SCRIPTA, Belo Horizonte, v. 10, n. 19, p. 15-24, $2^{\circ}$ sem. 2006. 